\title{
Can Technology-rich Spaces Support Multiple Uses?
}

\author{
Nadia Pantidi \\ The Open University \\ Walton Hall \\ Milton Keynes MK7 6AA UK \\ k.pantidi@open.ac.uk
}

\author{
Hugh Robinson \\ The Open University \\ Walton Hall \\ Milton Keynes MK7 6AA UK \\ h.m.robinson@open.ac.uk
}

\author{
Yvonne Rogers \\ The Open University \\ Walton Hall \\ Milton Keynes MK7 6AA UK \\ Y.Rogers@open.ac.uk
}

\begin{abstract}
A number of technology-rich spaces have been designed and created over the last few years with the purpose of supporting and enhancing learning, collaboration, community participation and a variety of everyday activities. Our research is concerned with how such spaces are used and whether they can support multiple uses. We report on an observational fieldwork study of a technology-rich multipurpose space based in a library. We examine its everyday use and discuss the tensions that were revealed in our analysis between anticipated and actual use. These are: (i) public versus private, (ii) play space versus meeting room and (iii) technology use versus non-use.
\end{abstract}

\section{Keywords}

Technology-rich spaces, multipurpose, ethnographic study.

\section{INTRODUCTION}

In the last few years, many 'technology-rich' spaces have been proposed as examples of future places for learning, working and socialising e.g., (Oblinger, 2006; JISC, 2006). Learning and, teaching spaces, such as classrooms and auditoriums, have been embedded with a diversity of new technologies, such as tablet PCs, whiteboards (Razmov, 2006), plasma screens, videoconferencing (CILASS), personal response systems and IP video systems (LeBaronHall Auditorium). A main aim is to promote collaborative learning through encouraging more interactions between students and teachers. Workspaces such as laboratories, meeting rooms and offices have been embedded with shared technologies such as tabletops, whiteboards, and wirelessly interconnected monitors to enable people to collaborate using a diversity of digital content (Streitz et al., 1999), (Stanford Group Spaces), (London Metropolitan Science Centre). Multi-user interactive surfaces e.g. (Izadi et al., 2003), interactive plasma displays e.g., (Churchill et al., 2003) and laptops and touch screens e.g., (Glasgow Caledonian Learning Cafe) have been placed in social spaces. Here, the intention has been to reinforce mechanisms and interactions already in place to improve community participation.

Another type of technology-rich space that is beginning to appear is one that is designed to be multi-purpose. A main idea is to make the space adaptable and flexible to people's changing needs and activities (e.g., InQbate; Saltire Centre). An advantage is that the same space can be configured for a variety

(c) The Author 2008.

Published by the British Computer Society of work, social and learning activities and for different user groups. However, while the idea of multi-purpose spaces is very appealing little is known as to how they are used in practice.

This paper reports on an observational fieldwork study of a technology-rich multipurpose environment, D-space, recently created as a new facility for visitors to a university library. The aim of the study was to observe how people used and appropriated the physical space, the technology embedded in it and each other. The study, carried out over a period of two months, revealed tensions between the anticipated and actual use. The paper discusses these in view of whether multipurpose, technologically-embedded spaces can work.

\section{THE STUDY}

The purpose of this study was to examine the reality of the everyday use of a multipurpose technology-rich space. The methodological approach was ethnographic (see, e.g., Fielding, 1993), involving participant observation of naturally occurring use and interaction together with semi-structured interviews with participants. The ethnographic approach ensured that the researcher attended to the taken-for-granted, accepted, and unremarked aspects of use and interaction, considering all activities as 'strange' so as to prevent prior assumptions and background from affecting their observations. No preliminary hypotheses were formed beforehand and no particular feature of use or interaction was given a priori significance.

The observations were carried out two to three days a week over a period of two months. The whole spectrum of daily activity was covered, with observing sessions in the morning, noon-early afternoon and late afternoon. Nevertheless, the majority of the data was gathered from the noon-early afternoon sessions, since the other two sessions revealed minimal activity. Activity and use was recorded by copious field notes. A schematic plan of the room was created to help capture any multiple interactions and movements through space and time. The semi-structured interviews, involved one of the managers of the space, a regular user and six first-time users - individuals who had never been in the space before or had only been there once.

The technology-rich space was situated in the library area of a University Campus. At the time of the study, it had been open for some 15 months, and its presence and availability was still strongly promoted around the University. As stated in a promotional leaflet, it is "a creative play area to experiment with and explore new ideas and share knowledge", a space that "brings together new technologies and ideas on how they could be used for learning and teaching now or in the future". The space measured $90 \mathrm{~m}^{2}$ and was situated at the far end (from the entrance) of the ground floor of the library. Its door is the first in a line of office doors and requires a key card in order to gain access. A big U-shaped couch in the centre of the room faces a 


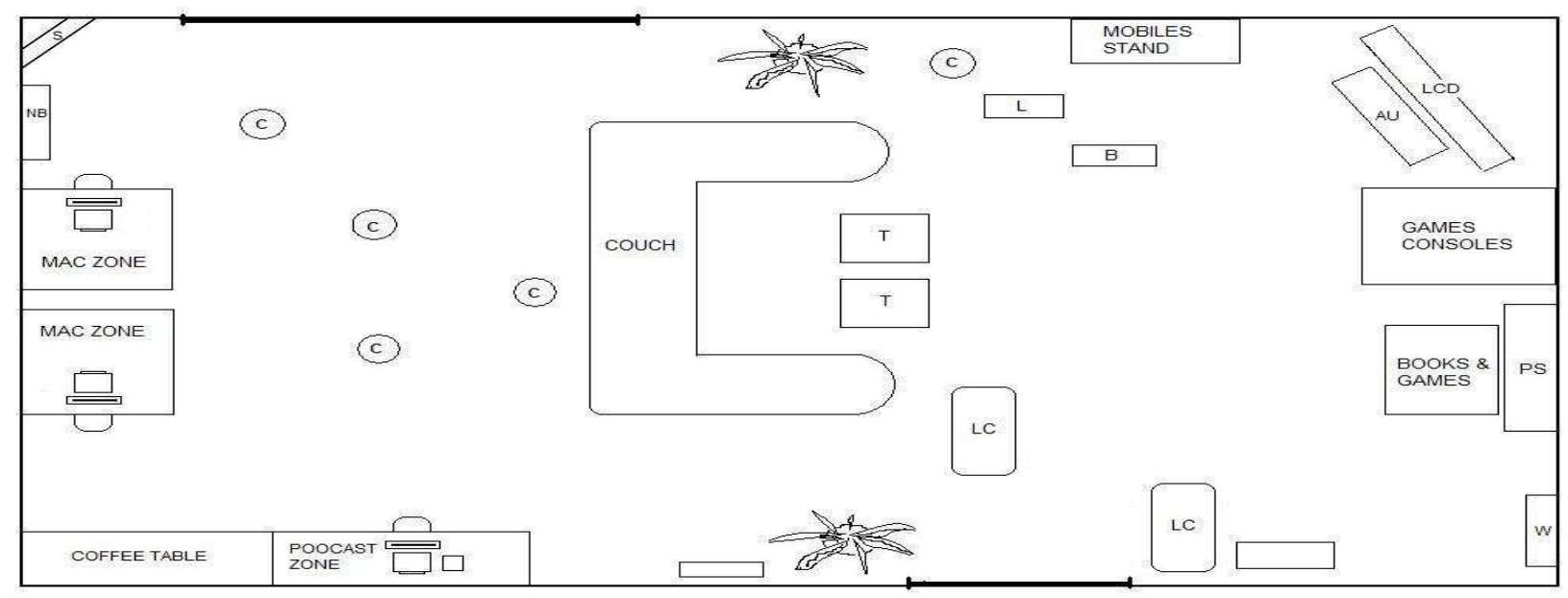

Figure 1. Schematic diagram of D-space: "C" stands for chairs, "LC" for lounge chairs, "T" for tables, "PS" for projector screen, "W" for whiteboard, "NB" for notice board, "L" for Lego's, "B" for books, "S" for shelves, "AU" for audio devices and "LCD" for LCD screen. The peripheral bold lines indicate the entrance and the window.

projector screen, a whiteboard and an LCD screen (see Figure 1). There is a large collection of current video games consoles (e.g., Wii, Xbox, PSP, Nintendo DS), a coffee machine, three desks with personal computers, books and magazines on education and technology, video games and other 'fun' technology objects such (e.g., iPod, a Nabaztag rabbit, a robot), as well as a collection of high-tech mobile phones. On the walls, and adjacent to each technology, there are labels and instructions describing how to use them. From the outside, the view into the space is obscured by a locked door, walls and a one-way window. There are, however, a few small 'port-hole' windows.

The overall findings from the interviews and observational sessions revealed that the space was not used in the way anticipated. Users of the space had a preference for using it primarily as a private meeting room. Furthermore, the actual use of the technologies was limited. We present our analysis and findings as three themes between proposed use and actual use: i) public versus private, ii) play space versus meeting room, iii) technology use versus non-use. The themes are articulated in terms of tensions between the rhetoric (the stated hopes, ambitions and intentions) of the space and the observed reality of its day-to-day use.

\subsection{Public versus private space?}

Planned use: D-space was designed to be public: it is a drop-in space that has a non booking policy. It was created to encourage groups of people with different backgrounds to get in touch and communicate their interests or their work in a neutral but yet cosy environment. The library was chosen for this purpose because it is a common building that "shelters" people from all departmental affiliations and issues of status. The space, in theory, accommodates teamwork and collaboration. The furniture is multifunctional and flexible; users have the freedom in reconfiguring -at least partly- the physical environment (chairs, tables). Display technologies are available for large groups of people.

Actual use: Was the space really public and did it support collocated action and collaboration? The observed use and activities that took place showed contradicting public versus private usage patterns of the space.
Demonstrating its public nature, there were times when the room was shared unobtrusively by two different groups having separate casual meetings and by one individual working at a PC at the same time when a group of two or three people were having a meeting. But, on the other hand, facial expressions, annoyed looks, stares and body language were indicators that there were times where users were disturbed by the presence of others. In most of the occasions where two groups of people (it was also the same for the case of one individual and one group) were coexisting in the space at the same time, two behavioural patterns were observed: whispering and "creating corners". Creating corners describes both the tendency of each group to be physically isolated in a corner of the room and also, when this was not possible, the tendency of groups to create corners where they did not exist, e.g., the couch. Even when the individuals/groups weren't "creating corners", they spoke in a low voice or whispered, suggesting that they didn't want to disturb the other group/person or because they didn't want to be heard. Moreover, there were occasions where people left the space because somebody was already there and returned immediately after the first group had left. This can be interpreted as the people not being comfortable sharing the space and also that there was some sort of ownership attributed to the pre-existing group in relation to the space.

One of the managers of the space mentioned that although she was afraid that there might be conflicts and complaints between groups, so far it seems "to be working really well and people don't mind sharing the space with others". Regular users of the space know that it is public and one interviewee also proclaimed that she enjoys that: "No, I find it stimulating; I don't mind if there are other people there or them overhearingI overhear sometimes! When I want to talk about something really private I go to other places e.g. meeting rooms. But most of our meetings are not that formal, they are more casual". On the other hand, non users or occasional users, all, with one exception, agreed during the interviews that it "doesn't feel as a public space", "it feels like a controlled room", "it feels like a room that you have to book", "it feels like a space designated for specific groups of people". When asked if they thought that the space can support collocated action, all of them replied that it depends on the activities involved and suggested that it would be feasible for quiet activities that do not involve more than two groups of people. Also, all of the participants commented that if 
one group uses the data projector and couch area for any type of activity, the coexistence of other group activities automatically gets more difficult or even impossible. Moreover, two of the participants stated clearly that if they entered the space and another group was already there, they would leave because it felt like they were interrupting and conversely, they would feel interrupted in a similar occasion.

The small size of the room meant that it did not favour many simultaneous group activities. When the interviewees were told that the space is a public, non-bookable space, they wondered about the need for a key card to enter. They tried to link the "public" attribute of the space with the already known public nature of the library building. A suggestion of changing the non-booking policy to booking also came up during the interview with the manager, who mentioned she gets requests from people to book the space for private activities or meetings ("we do get requests from people to book the room and I always go back to them and explain that we do have a non booking policy, (...) and they are usually fine with that and they will either come back and say we understand and still come and use the room or they will find a meeting space that they can book").

\subsection{Play space versus meeting room?}

Planned use: The designers had planned the space to be a place to experiment with the various technologies, and to consider how they might support learning and studying activities, for example, using Wii, Second Life or the robot. As stated by the manager, the aim was to provide "a creative play space with examples of technologies that could have educational application so that people could come in and have hands on, and have a play and just get familiar with".

Actual use: The space was used primarily as a meeting room and not in the intended way as a play space. In more than half of the observed cases, the space was used as a cosy meeting room; small groups of people sat on the couch or the comfortable chairs, discussing personal and work related subjects while having coffee. The majority of the observed uses was of people reading, being interviewed, having coffee or working in the PC area. Only twice in the period of two months was it used as a play space: both times two/three students were playing with the Wii console during or after their lunch break. There were also several occasions where people came in to the space with the intention of playing but were deterred by an informal meeting that was already in progress.

The observational data reveal a pattern of use that is not consistent with the originally intended use of the space. However, a selection of responses stemmed from the interviews with infrequent users. When asked to give a label to the room, they replied i) meeting room (three of them), ii) play space (two of them) and iii) mixed lounge room (one of them). It appears that their answers were guided from what was happening in the space when they were using it. For example, the regular user's response when asked what she usually does in the space when visiting replied: "Chatting at lunch breaks; mainly informal meetings with co-workers to talk about running projects and planning papers. Recently, I used the projector to do a dry run of a presentation in one of my supervision meetings". She also added that she has never used any of the game consoles and that she doesn't intend to because she is not interested ("I was never a gamer").

\subsection{Technology use versus non-use?}

Planned use: The technology was placed into the space to encourage visitors to try them out by themselves. To help those not familiar with the technologies various guides and instructions were provided.

Actual use: Our observations showed that the visitors were often intimidated and afraid of touching the technology inside the space. The most used technology was the computers. These were used mainly by individuals. When groups were involved, they used the computers to do a presentation or to make information visible for the whole group.

There were occasions when people entered the space very enthusiastically to try out all the technologies. They interacted with most of them (game consoles, mobiles, computers, IPod) but did not get very far with getting them to work. They read the relevant instructions and retried but failed again and finally ended up calling the manager for assistance. In the interview, the manager acknowledged : "...after a couple of events where we invited people to come and have a look around, we realised that there were a lot of users who were really scared of touching anything unless there was someone there to explain it to them, so we started offering facilitator staff sessions". What the manager described vividly as "really scared" is only one aspect of how people feel when trying to interact with the technology; another aspect, as the observation showed, is feeling incompetent.

The infrequent users reported feelings of incompetency even though they were familiar with the technology in the space. They had used most of the applications in the past and some quite regularly. Despite their acquaintance and previous experience, they were not able to work out how to use the same technology in the space.

These findings suggest that although cosy and comfortable, the affordances of the space lack inviting clues that would encourage users to know how to interact with the technology. Instead, the technology appears more like a shop window display that looks nice but cannot be touched. Finally, the study has shown how people will often appropriate technology for their own rather than intended use.

\section{CONCLUSION}

Our study has shown how a multi-purpose technology-rich space, situated in a university library, was used in different ways from how it had been anticipated. Rather than being used to experiment with a diversity of new technologies to think about their implications for supporting learning, it was appropriated primarily as a meeting space. Furthermore, very little of the available technology was played with.

Various tensions exemplify this discrepancy between the anticipated and actual use of the space. For example, despite the way the technologies were visibly laid out to be 'on display', with highly visible printed instructions next to them inviting visitors to try them out, the participants were often uncertain, and at times appeared to be intimidated by the choice on offer. Instead, they preferred to stay in their comfort zone, by appropriating familiar uses of the technology and physical space; for example, sitting on the sofa, using the data projector to have a meeting.

Why do such tensions arise between anticipated and actual use? One reason is that we often fail to notice the ways in which space constrains or enhances what we intend to accomplish, because we habitually take space arrangements for granted. Strange and Banning (Strange, 2002) asserted that "although features of the physical environment lend themselves theoretically to all possibilities, the layout, location, and arrangement of space and facilities render some behaviours more likely and thus more probable than others". This appears 
to have been what happened with D-space; its location, the arrangement of the space and the technology rendered it more of a private meeting room than a public play space. The locked door, the walls, the one-way window, all contributed to creating a "private effect" and in turn, the visitors constructed their own private identity of the space.

The way groups "created corners" even in round and open ended spots in D-space suggested an uncomfortable coexistence of two or more parties in the same physical space. Such awkwardness did not lend itself to spontaneous interaction and collaboration between the groups. The way the regular visitors used the space might also have set an example to others, suggesting how it should be used. It is well known how people establish behavioural routines according to the space they are in and depending on the existence/absence of other people. Furthermore, the strong associations with a library space may have made it awkward for people to feel at ease playing computer games in it - albeit to consider how they might be used to support learning in various ways.

Thus, it appears that multi-purpose technology-rich spaces, such as D-space, can be ambiguous to onlookers, sending out mixed messages as to how to use them. On the one hand, they provide many visual cues of what is on offer that can be tempting to have a look at. On the other hand, they may not offer enough clues or direction about their usage, making it difficult to know how to behave. D-space was full of cues and clues but which appeared to be counter-productive, as astutely observed by one the interviewees: "it is schizophrenic, not sure what it is". It maybe that technology-rich spaces that are designed with a specific purpose in mind (e.g., a social gathering place to watch and interact with large screen broadcasts) are more successful than those that are designed to be multi-purpose, providing many ways of using them but in underspecified ways - another example of the paradox of choice where less may be more (Schwartz, 2004).

\section{REFERENCES}

Churchill, E.F., Nelson, L., Denoue, L., and Girgensohn, A. "The Plasma Poster Network: Posting Multimedia Content in Public Places." Proceedings of INTERACT 2003, Ninth IFIP TC13 International Conference on Human-Computer. Zurich, Switzerland: IOS Press, 2003. 599-606.

CILASS:http://www.jisc.ac.uk/media/avfiles/programmes/elear ning_innovation/cilass_wm.wmv.

Fielding, N. "Ethnography." In Researching Social Life, by N. Gilbert. Sage, 1993.
Glasgow Caledonian Learning Café:

http://www.jisc.ac.uk/media/documents/publications/learningsp aces.pdf .

InQbate: http://www.inqbate.co.uk/ .

Izadi, S., Brignull, H., Rodden, T., Rogers, Y., Underwood, M. "Dynamo: A public interactive surface supporting the cooperative sharing and exchange of media." Proceedings of UIST 2003, Symposium on User Interface Software and Technology, November 2-5. Vancouver, Canada: ACM Press, 2003. 159-168.

JISC, e-Learning and Innovation Team. "Designing spaces for effective learning." Proceedings of JISC Conference 2006. 2006.

LeBaronHall Auditorium:

http://www.educause.edu/Chapter22.IowaStateUniversity\%3A LeBaronHallAuditorium/11920.

London Metropolitan Science Centre:

http://www.jisc.ac.uk/media/avfiles/programmes/elearning_inn ovation/science_centre_qt.mov .

Oblinger, D. Learning Spaces. Educause, 2006.

Razmov, V., Anderson, R. "Pedagogical Techniques Supported by the Use of Student Devices in Teaching Software Engineering." Proceedings of 37th ACM SIGCSE Technical Symposium on Computer Science Education. Houston, Texas: ACM Press, 2006. 344-348.

Saltire Centre:

http://www.jisc.ac.uk/media/avfiles/programmes/elearning_inn ovation/saltire wm.wmv.

Schwartz, B. The Paradox of Choice:Why More is Less. Ecco, 2004.

Stanford Group Spaces:

http://www.educause.edu/Chapter35.StanfordUniversity\%3AGr oupSpaces/11933.

Strange, C.C., and Banning, J.H. "Educating by Design: Creating Campus Learning Environments That Work." San Francisco: Jossey-Bass, 2002.

Streitz, N., Geißler, J., Holmer, T., Konomi, S., MüllerTomfelde, C., Reischl, W., Rexroth, P., Seitz, R., and Steinmetz, R. "i-Land: An Interactive landscape for creativity and innovation." Proceedings of CHI'99 ACM Conference on Human Factors in Computing Systems. New York: ACM Press, 1999. 120-127. 